\title{
Evaluation of Internal Cracks and Collapse in Poplar Wood (Populus nigra) during a Conventional Drying Process with Ultrasonic Inspection
}

\author{
Saeid ESHAGHI, Hadi DASHTI*, Mahdi SHAHVERDI \\ University of Tehran, Faculty of Natural Resources, Department of Wood and Paper Science and \\ Technology, Karaj, Iran; hadidashti@ut.ac.ir ("correspondingauthor)
}

\begin{abstract}
In this research, internal cracks and collapse of wood, formed during drying process, were measured using ultrasonic inspection. For this purpose, seven poplar (Populus nigra) small blocks were dried, according to a time-based schedule. Ultrasonic waves' propagation velocity was measured at both parallel and perpendicular to grain directions, using Sylvatest ultrasound device, during kiln drying process. Results showed that in all dried blocks, waves' propagation velocity in the parallel direction was higher than in the perpendicular direction to grain. Ultrasonic waves' propagation test for non-destructive identification of internal cracks, which occurs in wood during drying process in the parallel direction, was more successful compared to the perpendicular direction. Using ultrasonic waves' propagation test for detection of collapse that occurs in wood during drying process was not useful.
\end{abstract}

Keywords: collapse, internal cracks, parallel and perpendicular to grain, ultrasonic waves, wood drying

\section{Introduction}

Ultrasonic test is a method with old history, which previously was used for predicting the condition of substances. However, given that the sound that is within human hearing range was used to identify big flaws, for identification of minute defections, scientists' mind turned to use of ultrasonic waves. Ultrasonic test is able to detect both internal cracks and collapse of a piece but it does not mean that this technique is necessarily the best method for all inspection cases.

Selection of the best method depended on the type of existing defect, shape and size of the test samples. For detection of internal flaws, ultrasonic techniques were vastly employed but they could be used for revealing small superficial cracks as well. Almost all the non-destructive testing methods, used for different materials and products were applicable for wood and wood composites. In fact, selection of the method depends on the application. For decisiveness in quality of wood products, as an accurate and quick technique, a non-destructive method could be used. Nondestructive testing (NDT) could be a good and accurate tool for wood characterization, during drying. Ultrasonic wave's propagation as a simple, low-cost and flexible method has application for assessment of wood and wood product properties.

Drying was a critical step in manufacturing hardwood lumber, especially when considering opportunities to improve recovery and reduce both degrades and unnecessary expenses (Fuller et al., 1994). Furthermore, ultrasonic waves were used in wood drying for approximate assessment of wood moisture content, superficial and internal cracks, control of wood drying process and specification of kiln's internal conditions. Ultrasonic test was implemented within the frequency range of $20 \mathrm{kHz}-100 \mathrm{MHz}$ but for tracing tiny defects, as far as possible higher frequencies were used.

De Oliveira et al. (2005) showed that ultrasonic wave's velocities were sensitive to material quality factors; hence this technique proved to be useful in process quality improvement. In addition, they showed that ultrasonic wave velocity was susceptible to changes in lumber's moisture content.

On the other hand, the main cause for collapse occurrence was the use of high temperatures at the first stages of drying process (Keey et al., 2000). Interior splitting of wood due to severe drying stresses was usually referred to as honeycombing. Collapse could usually be considered as a source of different percentages of shrinkage that can consequently cause emerging of internal checks in dried wood. It also worth noting that some species were very susceptible to collapse, through wood elements (e.g. oak), and during drying (Langrish and Blakemore, 2008; Perre 2007; Yang and Fife, 2003; Yi-Qiang, 2005). This is one of the worst drying defects that unfortunately could not be discovered from superficial examinations. The presence of internal checks could significantly affect the ultrasonic velocity.

Fuller et al. (1994) in their study of honeycombing and superficial defects, using ultrasonic as a non-destructive test during drying of red oak wood, reached good results in determining defects by ultrasonic method (Fuller et al., 1994; Ross and Pellerin, 1994; Wang and Chen, 2001). 
142

Many hardwoods within-ring internal checking and collapse occurred at the start of drying and hence well above the fiber saturation point (Tiemann, 1913). The driving mechanism for collapse and internal checking in hardwoods was water tension in cell's water columns (Tiemann, 1915).

Fuller et al. (1994) has shown a strong relationship between the occurrence of honeycomb and surface checks along excessively long sound transmission times.

Despite numerous studies conducted on wood moisture content monitoring by ultrasonic technique, the effects of internal checks (honeycombing) and collapse for ultrasonic inspection of wood moisture content remained neglected. In this research, ultrasonic wave's technique was employed for non-destructive evaluation and detection of internal cracks and collapse in poplar wood (Populus nigra).

\section{Materials and methods}

\section{Sampling}

Seven samples with dimensions of $100 \times 50 \times 25 \mathrm{~mm}$ $(\mathrm{L} \times \mathrm{W} \times \mathrm{H})$ from $P$. nigra cultivated in western Karaj (Taleghan) were cut using a band saw. To reduce moisture exchange with the environment, the cross sections of samples were coated with epoxy resin. The initial moisture content of blocks was in range of 80-100\%.

\section{Drying condition}

To dry the samples, a time-based schedule was used. In this schedule, two steps for 46 hours were used. In the first step, the samples for 36 hours were exposed to $82^{\circ} \mathrm{C}$ dry-bulb temperature and relative humidity (RH) of $50 \%$. In the second step, samples were exposed for 10 hours to $82^{\circ} \mathrm{C}$ dry-bulb temperature and $\mathrm{RH}$ of $40 \%$. A laboratory kiln with a conventional drying method was used for drying woods.

\section{Ultrasonic waves' propagation test}

In this method, ultrasonic wave's techniques with high frequencies were sent inside the piece. By putting the probes on the piece, sonic waves were sent inside it and in case there was flaw inside the wooden samples (due to impedance change) it caused partial reflection of the whole waves.

Ultrasonic waves' propagation velocity was measured in the two directions, parallel and perpendicular to grain, using the 9906-015 ultrasound device model of Sylvatest (Fig. 1). The waves' propagation velocity in the samples was measured at 12 hours time intervals. To reduce the waves diffraction and to conduct them in the desired direction (parallel or perpendicular to grain), the probes' end was covered with grease.

Before measurements, a hole with $5 \mathrm{~mm}$ diameter and $\mathrm{l}$ $\mathrm{mm}$ depth was drilled on each side of the blocks. The holes were made by a conic shape drill. The end of Sylvatest probes was coated by grease to avoid air gap between the block and the transducers that could lead to provide better transmission of the ultrasonic wave at the interface. For each block, every measurement was repeated twice and means results were reported. On Fig. 1, the probes were placed in center of sections to measure ultrasonic waves' propagation velocity through the parallel and perpendicular to grains.
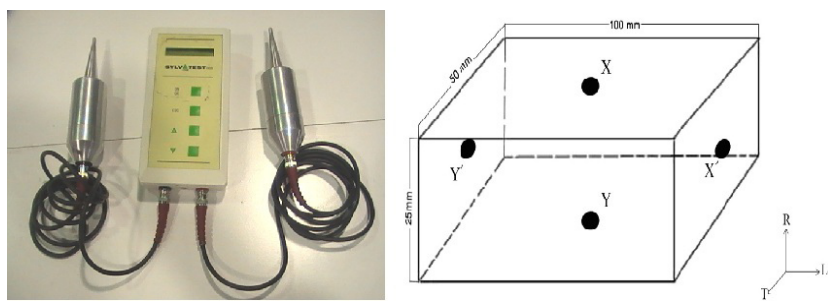

Fig. 1. The Sylvatest device (model 9906-015) and A schematic picture of probes' locations

\section{Visual inspection and scanning electron microscopy (SEM) studies}

After non-destructive testing of blocks, the occurrence of internal checks was assessed by slice cutting method. For this purpose, the dried blocks were cross cut into $20 \mathrm{~mm}$ thick slices, using a thin kerf band saw. Scanning electron microscopy (SEM) technique was applied to examine the effect of drying on collapse phenomenon in poplar wood.

\section{Results and discussion}

Ultrasonic waves' propagation velocity and fibers' direction

In all the dried blocks in this schedule, ultrasonic wave propagation velocity in parallel direction was greater than in perpendicular direction to grain. In green wood, waves' propagation velocity in parallel direction varied within range of $3500-4000 \mathrm{~m} / \mathrm{s}$ and in perpendicular direction, in contrast, values were within the range of $800-1500 \mathrm{~m} / \mathrm{s}$. Ultrasonic wave propagation velocity in parallel direction was on average three times higher than its amount in perpendicular to grain. In dry condition, the waves' propagation velocity in the either parallel or perpendicular to grain varied within $567-5170 \mathrm{~m} / \mathrm{s}$ and $155-1948 \mathrm{~m} / \mathrm{s}$, respectively.

As regards, results of this study were consistent with results obtained by De Oliveira et al. (2005). The reason for high ultrasonic waves propagation velocity increase in parallel direction compared to perpendicular to grain was the presence of an air layer in wave's path (lumens) during transfer of these waves through the perpendicular to grain direction.

\section{Ultrasonic waves' propagation velocity and wood drying cracks}

Sound velocity changes through the parallel and perpendicular to grain in wooden samples during drying process are shown in Fig. 2. In almost all the blocks, in the early stages of wood drying process, a decrease in ultrason- 

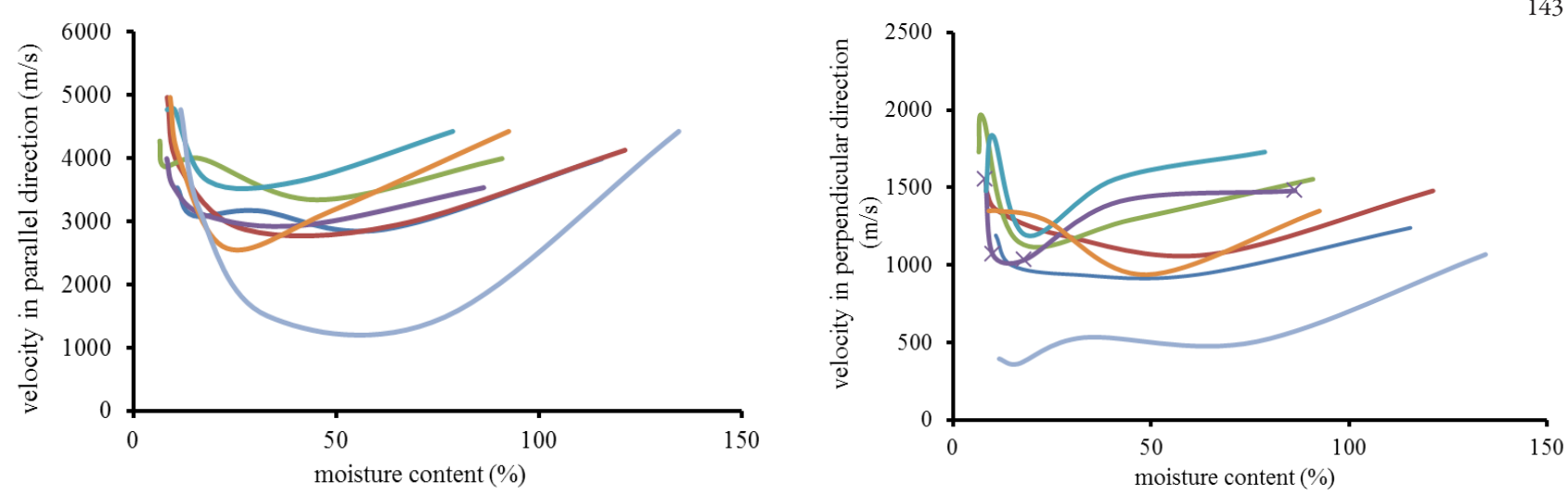

Fig. 2. Changes in the wave velocity vs. moisture content in the parallel (left) and perpendicular to grain (right) directions
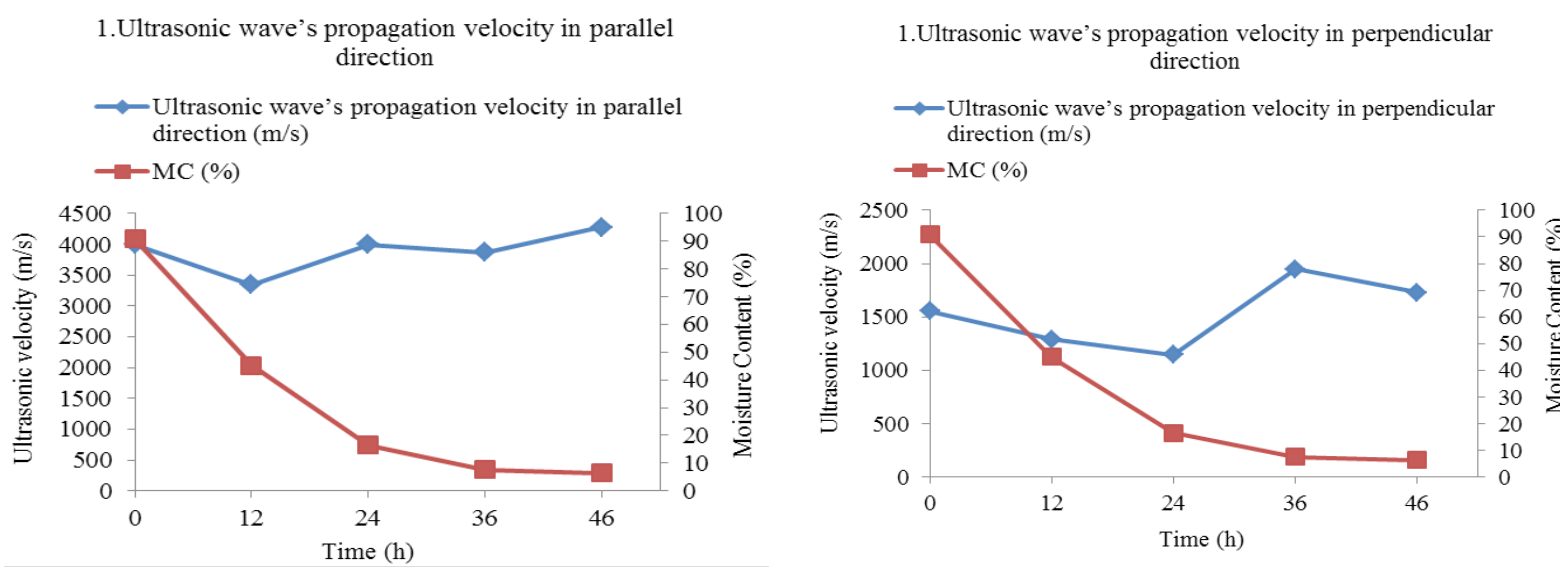

2.Ultrasonic wave's propagation velocity in parallel direction

2.Ultrasonic wave's propagation velocity in perpendicular direction

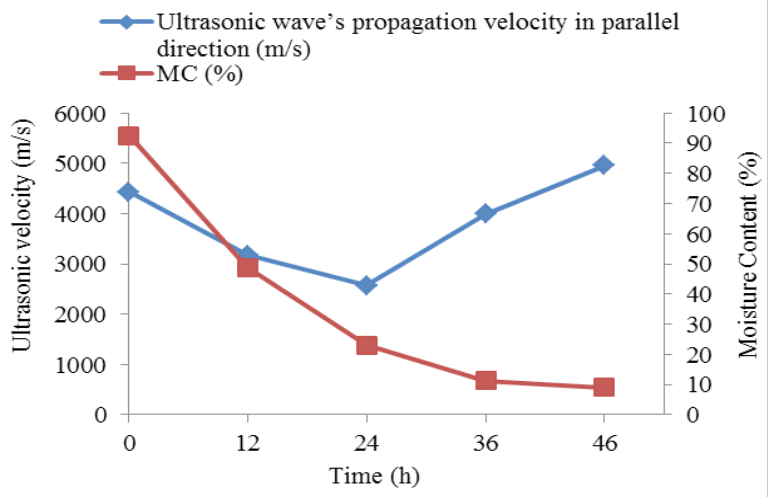

3.Ultrasonic wave's propagation Ultrasonic velocity in parallel direction

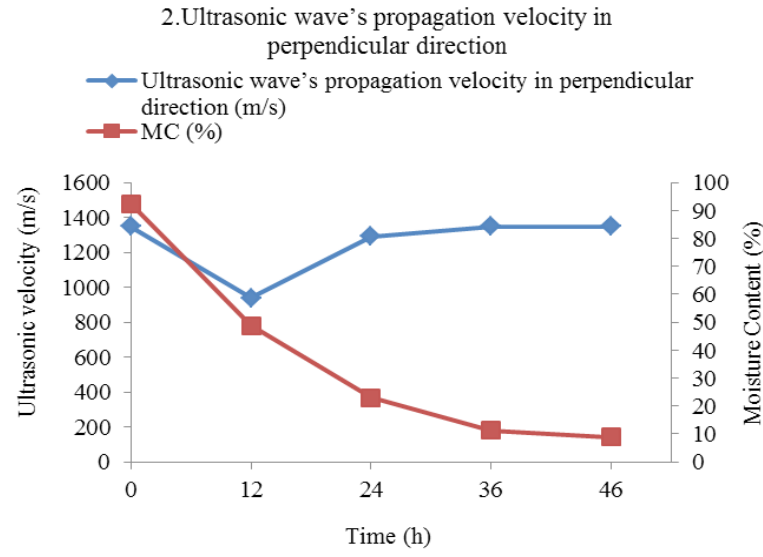

3.Ultrasonic wave's propagation velocity in perpendicular direction
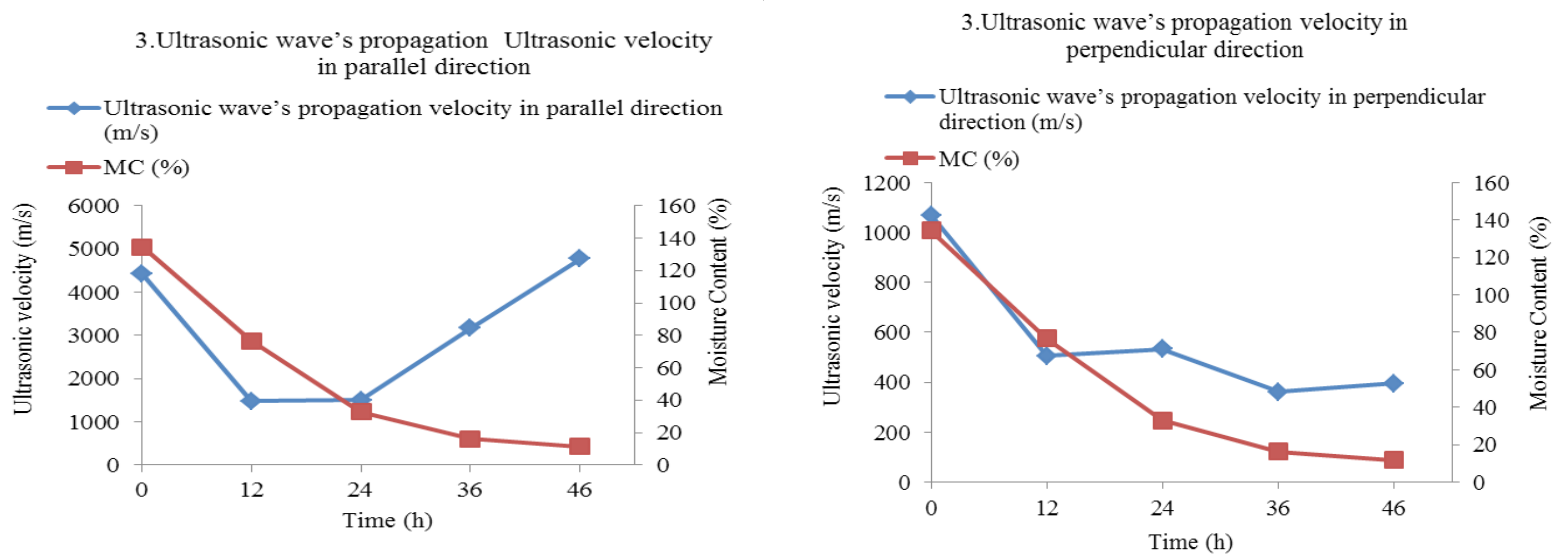

Fig. 3. Sound velocity changes in parallel and perpendicular to grain in wooden samples during drying process. ( 1 and 2 ) specimens containing collapse, (3) specimens containing internal crack 
144

ic waves' propagation velocity occurred after 12 hours and then the waves' propagation velocity gradually increased. As it seems the reason for this decrease was the formation of tiny superficial cracks occurring in the beginning of wood drying process.

Ultrasonic waves' propagation test in parallel to grain direction in detection of superficial and internal cracks was more successful than the same test in perpendicular to grain direction. The extent of ultrasonic waves' propagation velocity due to emergence of superficial and internal cracks in waves' propagation test in parallel direction was greater. In fact, ultrasonic waves' propagation test in perpendicular direction in non-destructive detection of internal cracks when will be effective that probes of the ultrasound device were positioned along the cracks.

Despite the occurrence of superficial and internal cracks in one of the blocks, waves' propagation velocity decline in perpendicular to grain direction did not show any difference from these waves' propagation velocity decline in sound blocks. Unlike results obtained by Fuller $e t$ al. (1994), which suggested the use of ultrasonic waves' propagation technique for detection of internal cracks (honeycombs) in red oak species as a suitable method. But, results of this research revealed that this technique for
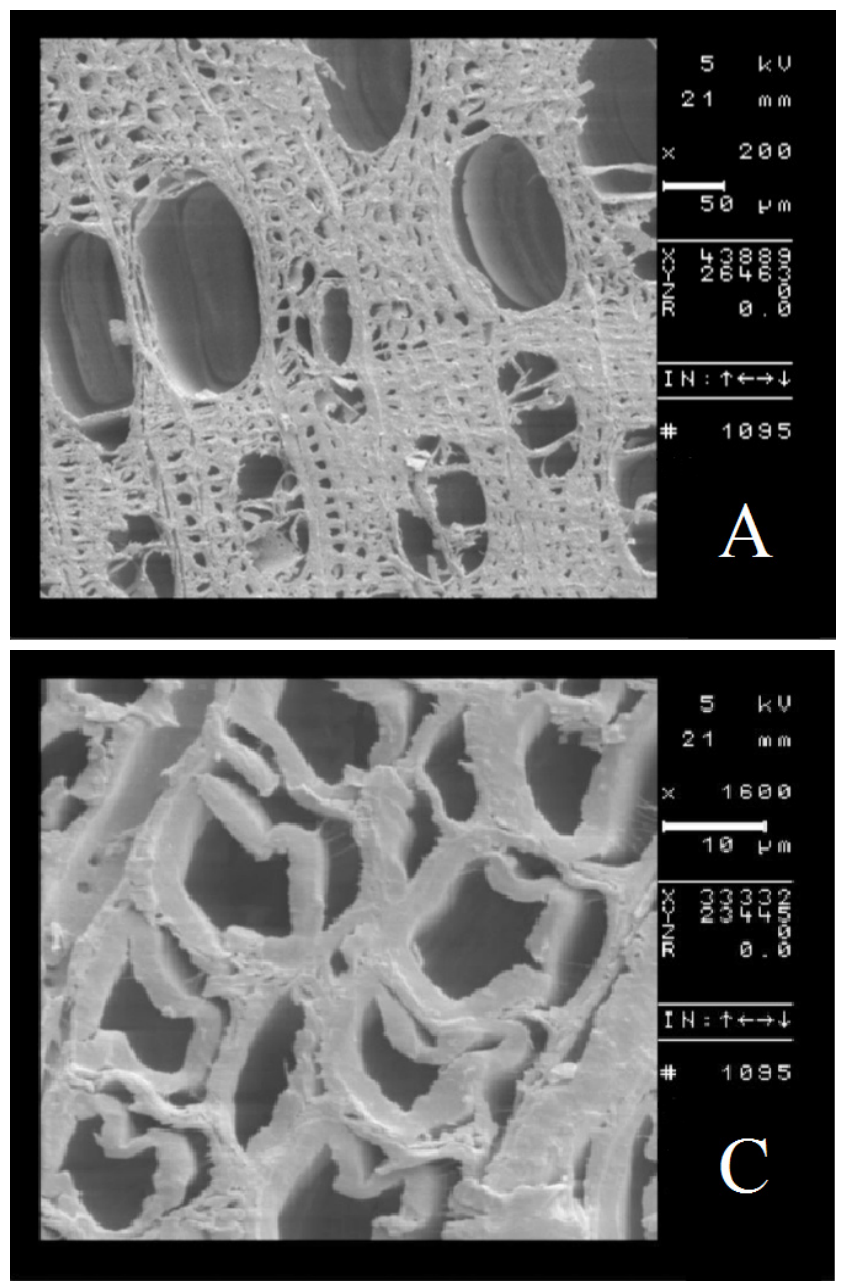

non-destructive detection of inner cracks in $P$. nigra species did not prove to be an accurate and efficient method.

Also a research by Booker (1994) showed that macroscopic cracks compared to microscopic cracks do not affect sound propagation that much. In addition, experiments conducted by Kawamoto (1996) showed that internal cracks detection was only limited to surfaces close to transducers. Therefore, it could be affirmed that while using ultrasonic waves' propagation technique for internal cracks detection, the test condition, particularly transducers location was of great impact.

\section{Ultrasonic wave's propagation velocity and collapse phenomenon}

SEM pictures of collapsed containing and collapse free specimens have been depicted in Fig. 4. As regards, severe deformations in wood cells, particularly vessel elements could be observed. Increase of capillary tension caused by pits with low diameters would result in collapse of wooden cells.

Moreover, some of the main reasons for this phenomenon were compression stresses and capillary tension. This phenomenon takes place as a result of a high dry-bulb temperature usage at the first stages of drying process. In fact,
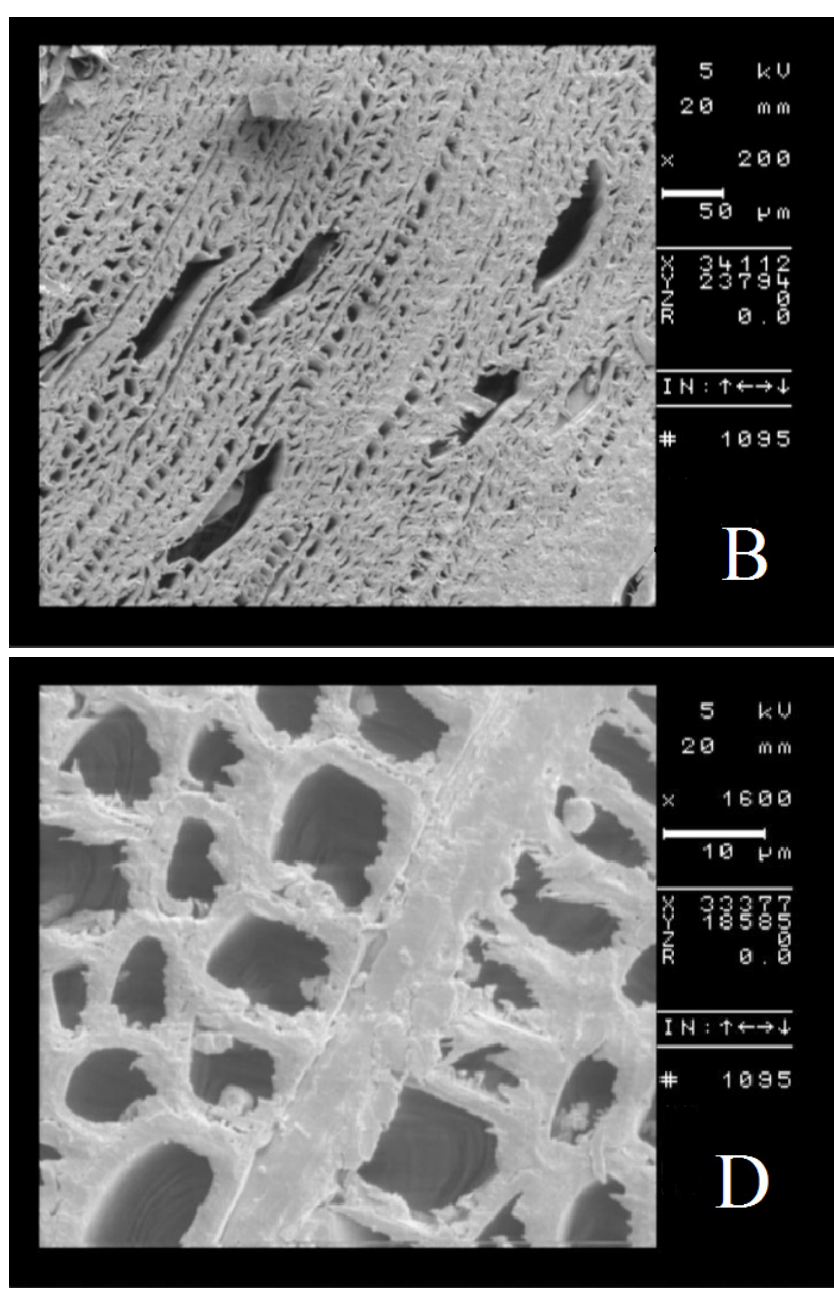

Fig. 4. SEM micrographs of samples cross section. A, C control specimens; B, D collapse containing specimens 
using a high dry-bulb temperature would result in faster bulk flow of free water and consequently more compression stresses than the allowable amount of wood compression strength, which would result in collapse among wooden cells. In spite of occurrence of collapse in these specimens, the ultrasonic wave velocity did not change through the both parallel and perpendicular to grain directions. With regard to occurring collapse that taken place at the first stages of the drying process, but there was no any significant relationship between wave velocities compared with time and MC.

In this research, superficial and internal cracks of wood in drying process were assessed using ultrasonic waves' test. Due to internal cracks in wood as a result of drying, ultrasonic waves' propagation velocity decreased. However, because of reciprocal effects of moisture and crack occurrence, analysis of wood drying cracks by means of these waves was very complicated. Occurrence of wood drying cracks caused sudden drop in ultrasonic waves' propagation velocity in early stages of wood drying process despite moisture decrease. In this research, ultrasonic waves' propagation test for non-destructive detection of collapse and internal cracks, in parallel direction was more successful compared to the test in perpendicular to grain direction. The reasons for contradictory results between different researches with regard to assessment of wood drying cracks using ultrasonic waves' propagation test (Booker, 1994; Fuller et al., 1994; Kawamoto, 1996) were: experimental conditions and probes' location (1); intensity and place of wood drying cracks occurrence (2).

\section{Conclusions}

Results of this research revealed that if probes of ultrasound device were not positioned along internal cracks, the inner cracks (honeycombs) could not be detected and assessed by means of ultrasonic waves' propagation. In spite of collapse's occurrence in some specimens and also its related deformations within wood cells, induced by using a high temperature at the first stages of the drying process, they had no significant effects on the wave velocity through the both parallel and perpendicular to grain directions. Given the obtained results from this research, it could be concluded that non-destructive application of ultrasonic waves' propagation in wood drying process depends on wood species, intensity and place of wood drying cracks, experimental conditions, and probes' location, which could be considered in future research.

\section{References}

Blakemore P, Langrish TAG (2008). Effect of pre-drying schedule ramping on collapse recovery and internal checking with Victorian Ash Eucalypts. Wood Sci Technol 42:473492.

Booker JD (1994). Acoustic emission and surface checking in Eucalyptus regnans boards during drying. Holz als Roh und Werkstoff 52:383-388.

De Oliveira FGR, Candian M, Lucchette FF, Salgon JL, Sales A (2005). A technical note on the relationship between Ultrasonic velocity and moisture content of Brazilian hardwood (Goupia glabra). Build Environ 40(2):297-30.

Fuller JJ, Ross RJ, Dramm JR (1994). Honeycomb and Surface Check Detection Using Ultrasonic Nondestructive Evaluation. Res. Note FPL-RN-0261. Madison, WI, 6 p.

Kawamoto $S$ (1996). Detection of acoustic emissions associated with the drying of wood. In: Proceedings of 10th International Symposium on Nondestructive Testing of Wood, August, Lausanne, Switzerland.

Keey RB, Langrish TAG, Walker JCF (2000). Kiln-Drying of Lumber. Springer, New York.

Perre P (2007). Experimental device for the accurate determination of wood-water relations on micro-samples. Holzforschung 41(2):214-204.

Ross P, Pellerin RF (1994). Nondestructive testing for assessing wood members in structures: A review. FPL-CTR-70 USADA, $40 \mathrm{p}$.

Tiemann HD (1913). Eucalyptus Lumber. Hardwood Record, Chicago, Sept 25 and Oct 10.

Tiemann HD (1915). Principles of kiln drying. Lumber World Review, Jan 15 and Sept 25.

Wang SY, Chen BJ (2001). The flake's alignment efficiency and orthotropic properties of oriented strand board. Holzforschung 55(1):97-103.

Yang JL, Fife D (2003). Identifying check-prone trees of Eucalyptus globulus Labill. Using collapse and shrinkage measurements. Austr For 66:90-92.

Yi-Qiang W, Kazuo H, Yuan L, Ying-chun C, Jian-ju L (2005). Collapse-type shrinkage characteristics in plantationgrown eucalypts: I. Correlations of basic density and some structural indices with shrinkage and collapse properties. J For Res 16(2):83-88. 